\title{
Tyrosine-phosphorylation of the 12th armadillo-repeat of $B$-catenin is associated with cadherin dysfunction in human cancer
}

\author{
KOHEI SHOMORI ${ }^{1,2}$, ATSUSHI OCHIAI ${ }^{3}$, SHINGO AKIMOTO ${ }^{1}$, YOSHINORI INO ${ }^{1}$, \\ KOYO SHUDO $^{1}$, HISAO ITO ${ }^{2}$ and SETSUO HIROHASHI ${ }^{1}$ \\ ${ }^{1}$ Pathology Division, National Cancer Center Research Institute, 1-1 Tsukiji 5-chome, Chuo-ku, Tokyo 104-0045; \\ ${ }^{2}$ Division of Organ Pathology, Department of Microbiology and Pathology, Faculty of Medicine, Tottori University, \\ 86 Nishi-cho, Yonago, Tottori 683-8503; ${ }^{3}$ Pathology Division, Research Center for Innovative Oncology, \\ National Cancer Center Hospital East, 5-1 Kashiwanoha 6-chome, Kashiwa, Chiba 277-8577, Japan
}

Received February 9, 2009; Accepted April 13, 2009

DOI: 10.3892/ijo_00000363

\begin{abstract}
Tyrosine phosphorylation of $\beta$-catenin, an intracytoplasmic cadherin-binding protein, causes disruption of the cadherin-mediated cell adhesion system in cancer cells. We identified that the c-erbB-2 protein activated by $\mathrm{TGF} \alpha$ was capable of binding to the 12th armadillo repeat (arm12) of $\beta$-catenin with increased phosphorylation-state level. We produced a monoclonal antibody, 4G7, which recognizes a phosphorylated-tyrosine residue (Tyr-654) located at arm12 of $\beta$-catenin. Tyrosine phosphorylation of the arm12 was detected after stimulation with TGF $\alpha$ in TMK-1. Immunoprecipitation analyses using $4 \mathrm{G} 7$, anti- $\beta$-catenin, $\alpha$-catenin, the c-erbB-2 gene product and phosphotyrosine antibodies indicated that tyrosine phosphorylation of the arm12 was closely correlated with dissociation between E-cadherin/ $\beta$-catenin and $\alpha$-catenin or the c-erbB- 2 gene product, but not with dissociation between $\beta$-catenin and E-cadherin. Immunocytochemical staining of TMK-1 cells using the 4G7 antibody revealed that tyrosine phosphorylation of the arm12 was localized at cell-cell contact sites of cancer cells transiently and only after TGF $\alpha$ treatment. Immunohistochemical localization of the 4G7 antibody was observed in cancer cells at the invasive front where they detached from cancer nests. These findings indicated that the tyrosine phosphorylation of arm 12 is a key marker of cadherin dysfunction and the 4G7 antibody may be useful in screening for a $\beta$-catenin phosphorylation ligand or tyrosine kinases.
\end{abstract}

Correspondence to: Dr Atsushi Ochiai, Pathology Division, Research Center for Innovative Oncology, National Cancer Center Hospital East, 6-5-1 Kashiwanoha, Kashiwa, Chiba 277-8577, Japan

E-mail: aochiai@east.ncc.go.jp

Key words: catenin, cancer adhesion, tyrosine phosphorylation

\section{Introduction}

E-cadherin is the major cell adhesion molecule expressed by epithelial cells and is essential for tight connection between cells (1). The cadherin-mediated cell adhesion system has been shown in vitro to act as an invasion suppressor system in cancer cells (2). The specific cytoplasmic domain of E-cadherin interact with catenin molecules comprising $\alpha-, \beta-, \gamma$ - and p120 catenin, which establish an intracellular linkage with the actin cytoskeleton (3-5). A decrease in the adhesive properties of the cadherin-catenin complex has been shown to be related to the loss of differentiation and subsequent acquisition of a higher motility and invasiveness of cancer cells $(6,7)$.

Cells have to regulate the strength of their adhesiveness, and post-translational modifications such as phosphorylation may be one mechanism of regulation (8). In v-src-transfected cells, $\beta$-catenin in the cadherin-catenin complex is preferentially tyrosine-phosphorylated, and the increased tyrosine phosphorylation of $ß$-catenin is apparently associated with a cadherin dysfunction (8-10). Treatment of adenocarcinoma cells with growth factor results in the accumulation of phosphorylated tyrosine residues on $\alpha$ - and $\beta$-catenin, concomitant with a loss of cadherin-mediated adhesion (11). These data suggest that the degree of tyrosine phosphorylation of $\beta$-catenin is a critical parameter controlling cadherin function in human cancer cells, possibly by regulating the association of cadherin with the cytoskeleton.

We previously reported that a c-erbB-2 gene product, which encodes a receptor tyrosine kinase, associated directly with carboxyl-terminal armadillo repeats of $\beta$-catenin (12-14). Transforming growth factor $\alpha(\mathrm{TGF} \alpha)$ treatment activated epithelial growth factor (EGF) receptors and c-erbB-2 protein and induced tyrosine phosphorylation of $\beta$-catenin. We found that the inhibition of association between $\beta$-catenin and the c-erbB-2 gene product via the introduction of the c-terminal half of the $\beta$-catenin gene resulted in decreased tyrosine phosphorylation of $\beta$-catenin, and increased cell-cell connections which prevented peritoneal dissemination in a SCID mouse model (14). 
Based on these studies, we hypothesized that the specific part of $\beta$-catenin containing tyrosine residues could be a candidate association site for the c-erbB-2 gene product. In order to confirm the signal transduction between c-erbB-2 and $\beta$-catenin, we produced a monoclonal antibody that recognizes the tyrosine-phosphorylated 12th armadillo repeat of $\beta$-catenin and examined the consequences of tyrosine phosphorylation of $\beta$-catenin on cadherin function, as well as the composition of the cadherin-catenin complex. We found that tyrosine phosphorylation of the 12th armadillo repeat of catenins altered cellular morphology and invasiveness in vivo.

\section{Materials and methods}

Cell culture. TMK-1, a human gastric cancer cell line, was cultured in RPMI-1640 medium (Life Technologies, Inc., Rockville, MD), supplemented with $10 \%$ heat-inactivated fetal bovine serum (FBS) (Life Technologies, Inc.), and a mixture of $100 \mathrm{U} / \mathrm{ml}$ penicillin-streptomycin (Life Technologies, Inc.). The cells expressed the c-erbB-2 gene product and included no mutated E-cadherin and B-catenin constituting the cadherin-catenin complex. Mouse myeloma cell line, SP2, and hybridoma cells were grown in RPMI1640 , supplemented with $20 \%$ heat-inactivated FBS, penicillin-streptomycin, and $0.5 \%$ hybridoma cloning factor (Origen International, Inc. Gaithersberg, MD).

Reagents. Anti- $\alpha, \beta$ and $\gamma$-catenin monoclonal antibodies (mAbs) were purchased from Transduction Laboratories (Lexington, KY). Anti-phosphotyrosine mAb (clone 4G10) was purchased from Upstate Biotechnology, Inc. (Lake Placid, NY). Polyclonal rabbit anti-c-erbB-2 gene product antibodies were purchased from Nichirei (Tokyo, Japan). Mouse non-specific immunoglobulin G1 was obtained from Sigma (St. Louis, MO). Goat anti-mouse or goat anti-rabbit horseradish peroxidase-coupled secondary antibodies were purchased from Zymed (San Francisco, CA).

Generation of recombinant proteins and in vitro binding assay with GST fusion proteins. Full-length and deletion mutant of $\beta$-catenin were amplified by polymerase chain reaction (PCR)-mediated mutagenesis with the following pairs of primers: BCT, HB-1 and HB-2; DN, HB-4 and HB-2; ARM1, HB-6 and HB-7; ARM2, HB-8 and HB-9; ARM12+11, HB-8 and HB-10; ARM11, HB-8 and HB-3; ARM12, HB-5 and HB-10; and subcloned into pGEX2TK (Amersham Phalmacia). The primers were: HB-1, 5'-ccggatc catggctactcaagctgat-3'; HB-2, 5'-cacccgggttacaggtcagtatcaa-3'; HB-3, 5'-gactcgagtcacagaggaccctgcagc-3'; HB-4, 5'-ccggatc ctctagtaataagccggct-3'; HB-5, 5'-aaggatccgctgcaggggtcctct gtga-3'; HB-6, 5'-caggatccaagaacaagatgatggtctg-3'; HB-7, 5'-ctgaattcacaaattgctgctgtgtccc-3'; HB-8, 5'-agggatcccgcatgga agaaatagttg-3'; HB-9, 5'-tcagatatccggaacaaaacagcagctg-3'; and HB-10, 5'-tcgaattctcggaacaaaacagcagctg-3'. The DC mutant was generated by digesting pGEXBCT with EcoRI and the remaining vector self-ligated. All the PCR products were sequenced. Glutathione-S-transferase (GST) fusion proteins were expressed in JM109, as described by Shibata et al (15).
Full-length or deletion mutants of ß-catenin as GST fusion proteins were coupled to glutathione agarose beads (Amersham Pharmacia) following the manufacturer's instructions and these GST fusion protein beads were incubated with TMK-1 cell lysates. After washing the beads thoroughly with lysis buffer, the bound proteins were eluted with Laemmli buffer, separated by sodium dodecyl sulfate (SDS)-polyacrylamide gel electrophoresis (PAGE) and incubated with a polyclonal anti-c-erbB-2 antibody.

In vitro phosphorylation of GST $\beta$-catenin mutants. Cells were lysed in ice-cold lysis buffer and the lysates were cleared by centrifugation. The supernatants were incubated with or without $\mathrm{TGF} \alpha(20 \mathrm{ng} / \mathrm{ml})$ (Upstate Biotechnology, Inc.) at $25^{\circ} \mathrm{C}$ for $30 \mathrm{~min}$ and subjected to immunoprecipitation with anti-c-erbB-2 antibody prebound to protein-G-sepharose at $4^{\circ} \mathrm{C}$ for $2 \mathrm{~h}$. The immunoprecipitates were washed three times with cold lysis buffer and once with phosphorylation buffer [20 mM HEPES (pH 7.5), $100 \mathrm{mM} \mathrm{NaCl}, 5 \mathrm{mM} \mathrm{MgCl}_{2}$, $5 \mathrm{mM} \mathrm{MnCl}_{2}, 10 \%$ glycerol and $0.1 \%$ Nonidet P-40]. The immune complexes were incubated with purified GST-fusion proteins $(2 \mu \mathrm{g})$ in $30 \mu \mathrm{l}$ of phosphorylation buffer containing $3 \mu \mathrm{M}$ ATP and $10 \mu \mathrm{Ci}\left[\gamma^{32} \mathrm{P}\right] \mathrm{ATP}(3000 \mathrm{Ci} / \mathrm{mmol}$; Ameresham Pharmacia) at $30^{\circ} \mathrm{C}$ for $30 \mathrm{~min}$. After stopping the reaction by adding $7 \mu 1$ of $5 \mathrm{X}$ SDS-sample buffer, phosphorylated GST alone and GST-fused ARM11 and ARM12 were eluted by boiling, resolved by SDS-polyacrylamide gel and detected by autoradiography.

Production of phosphorylation state-specific $m A b$. Synthetic peptides, both tyrosine phosphorylated and non-phosphorylated, corresponding to amino acid residues 83-91 and 647-659 of human B-catenin were purchased from the Peptide Institute, Inc. (Osaka, Japan). The phosphotyrosine (pY)-containing peptide CRNEGVAT-pY-AAAVL, which corresponds to the 13 amino acids surrounding Tyr 654 of $\beta$-catenin, plus an $\mathrm{N}$-terminal cystein for coupling ( $\mathrm{p}$-arm12), and an identical non-phosphate-containing peptide (non-p-arm12) were synthesized by the Peptide Institute, Inc. The phosphotyrosinecontaining peptide DGQ-pY-AMTRAC (other-p-peptide), corresponding to the $\beta$-catenin binding site surrounding tyrosine 86 of $\beta$-catenin, was synthesized in the same way (Fig. 3a).

The p-arm12 peptide was coupled to keyhole limpet hemocyanin (KLH) with glutaraldehyde. The p-arm12-KLH emulsified in complete Freund's adjuvant (Sigma) was injected into female BDF1 mice, aged 6 weeks, (Nippon Crea Inc., Tokyo, Japan) intraperitoneally (i.p.). The mice were given a booster of p-arm12-KLH emulsified in incomplete Freund's adjuvant (Sigma) i.p. in three times at 2 -week intervals. Three days after the final intravenous boost of p-arm12-KLH in an aqueous solution, spleen cells from each mouse were fused with a mouse myeloma cell line, SP2/0-Ag14, using polyethylene glycol 1300-1600 (Sigma), as described by Galfre and Milstein (16). The hybridomas producing antip-arm12 peptide antibodies were screened with an enzyme linked immunosorbent assay (ELISA) in microtiter plates coated with p-arm12. The monoclonal antibody, 4G7, reacting with the p-arm 12 specifically was selected. Isotyping using a Mouse Monoclonal Isotyping kit (Amersham Pharmacia Ltd., 
Amersham, UK) revealed this antibody to be of the $\mathrm{IgG} 1 \kappa$ class.

ELISA. Microtiter plates were coated overnight with $50 \mu 1$ of each synthetic peptide solution $(1 \mu \mathrm{g} / \mathrm{ml}$ in PBS, containing $0.1 \%$ sodium azide) at $4^{\circ} \mathrm{C}$, blocked with $2 \%$ bovine serum albumin (Sigma) in PBS at $4^{\circ} \mathrm{C}$, and reacted with the primary antibodies. Then, the immunoreactivity of the antibodies to each peptide was determined by ELISA, as described previously by Engvall (17).

Immunoprecipitations. Confluent TMK-1 cells in 100-mm dishes were serum-starved in medium containing $0.1 \%$ FBS. In order to maximize differential tyrosine phosphorylation of $\beta$-catenin isolated from TGF $\alpha$-treated cells, a phosphotyrosine phosphatase inhibitor, sodium $o$-vanadate $\left(\mathrm{Na}_{3} \mathrm{VaO}_{4}\right)$, was added at a final concentration of $1 \mathrm{mM}$ prior to stimulation of $\mathrm{TGF} \alpha$, and was present at all subsequent steps pre- and post lysis. Cells were incubated with or without TGF $\alpha$ at $100 \mathrm{ng} / \mathrm{ml}$ for $30 \mathrm{~min}$ at $37^{\circ} \mathrm{C}$ with sodium $o$-vanadate. Cells were washed twice with ice-cold PBS immediately after TGF $\alpha$ stimulation and solubilized with $1 \mathrm{ml}$ lysis buffer consisting of $10 \mathrm{mM}$ HEPES, $167 \mathrm{mM} \mathrm{NaCl}, 20 \mathrm{mM} \mathrm{NaF}, 20 \mathrm{mM}$ EGTA, $1 \%$ (w/v) Nonidet P-40, 1\% (w/v) Triton X-100, $5 \mathrm{mM}$ sodium pyrophosphate, $60 \mathrm{mM}$ 2-glycerophosphate, $1 \mathrm{mM}$ phenylmethylsulfonyl fluoride, $1 \mu \mathrm{g} / \mathrm{ml}$ aprotinin, $1 \mu \mathrm{g} / \mathrm{ml}$ pepstatin, $1 \mu \mathrm{g} / \mathrm{ml}$ leupeptin and $1 \mathrm{mM} \mathrm{Na}_{3} \mathrm{VaO}_{4}$. Five micrograms of anti- $\beta$-catenin $\mathrm{mAb}$ was used to immunoprecipitate $\beta$-catenin from $1 \mathrm{ml}$ of cell lysate. The c-erbB-2 gene product and E-cadherin were also immunoprecipitated from a TMK-1 cell lysate using anti-c-erbB-2 and E-cadherin antibodies in a similar fashion, respectively. The precise methods for immunoprecipitation were described elsewhere (12).

Immunoblotting. Growth factor-stimulated cells were treated as for immunoprecipitation. Cells were subsequently washed and solubilized in $100 \mu \mathrm{l}$ of an electrophoresis sample buffer and denatured at $100^{\circ} \mathrm{C}$ for $5 \mathrm{~min}$. Samples were resolved in $7.5 \%$ acrylamide $/ 0.175 \%$ bis-SDS-polyacrylamide electrophoretic gels at a constant voltage followed by transfer to PVDF membranes (Millipore, Bedford, MA) and immunostaining was processed using enhanced chemiluminescence detection reagents (Amersham Pharmacia Ltd.). The following dilutions were used: anti- $\beta$-catenin $\mathrm{mAb}$ was used at 1:500 dilution; anti- $\alpha$-catenin $\mathrm{mAb}$ was used at 1:2000 dilution; antiE-cadherin mAb (HECD-1) was used at 1:500 dilution; The anti-c-erbB-2 gene product polyclonal $\mathrm{Ab}$ was used at 1:200 dilution; Anti-pY (4G10) mAb was used at 1:500 dilution; 4G7 antibody was used at 1:250 dilution of hybridoma supernatant; goat anti-mouse or goat anti-rabbit horseradish peroxidase (HPO)-coupled secondary antibodies were used at $1: 1000$ dilution.

Immunofluorescence. TMK-1 cells were plated onto glass cover slips. The cells were rinsed in PBS and fixed in $4 \%$ paraformaldehyde in PBS for $30 \mathrm{~min}$ and then washed three times with PBS. Cells were permeabilized with $0.5 \%$ Triton X-100 in PBS for $30 \mathrm{~min}$ at room temperature before antibody treatment. After rinsing with PBS, cells were labeled with the primary antibodies dissolved in $2 \%$ normal swine a

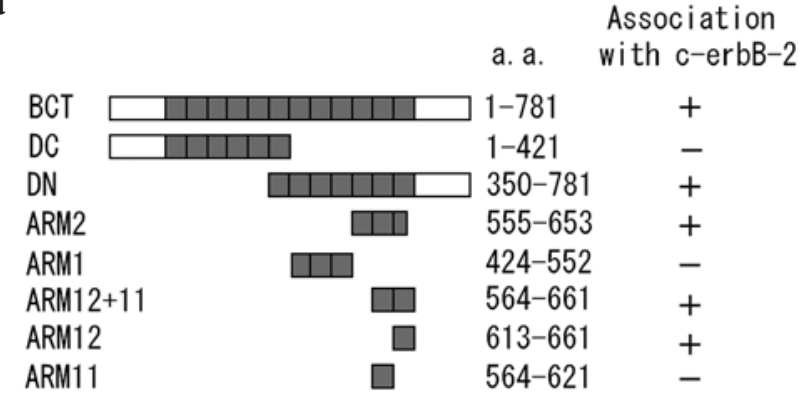

b

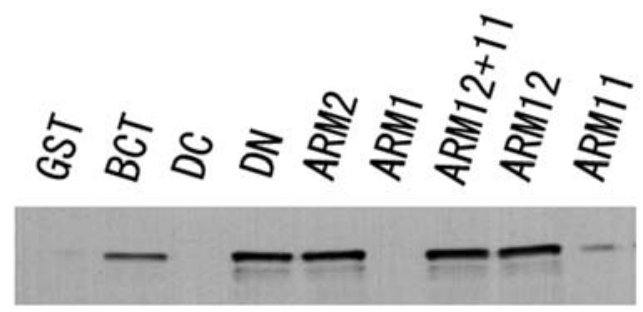

Figure 1. Association of c-erbB-2 protein with the 12th armadillo repeat of ß-catenin. (a) Schematic representation fo full-length and deletion mutants of B-catenin protein and summary of their ability to associate with c-erbB-2 protein. Shadowed boxes indicate armadillo repeats. (b) Association of cerbB-2 protein with full-length and mutant $\beta$-catenin proteins. Full-length or deletion mutants of $\beta$-catenin as GST fusion proteins were expressed and coupled to glutathione-agarose beads, which were separated by SDS-PAGE and immunoblotted with a polyclonal anti-c-erbB-2 antibody.

serum (NSS; Dako, Glostrup, Denmark)/PBS overnight at $4^{\circ} \mathrm{C}$. Immunoreactivity of the $4 \mathrm{G} 7$ antibody was detected with a biotinylated goat anti-mouse antibody (Vector Laboratories, Inc. Burlingame, CA) followed by FITC-conjugated avidin (Vector). Immunofluorescence was detected using a laser confocal imaging system (Carl Zeiss, Jena, Germany).

In order to confirm the specificity of the 4G7 antibody by immunofluorescence, it was separately preincubated by PBS of a 0.1 volume of $1 \mathrm{mM}$ solution of p-arm12 and non-p-arm12 peptides for $1 \mathrm{~h}$ on ice prior to being applied for immunostaining.

Immunohistochemistry. For preservation of phosphorylated tyrosine residues, fresh surgical specimens were treated with $1 \mathrm{mM}$ sodium $o$-vanadate in PBS as soon as possible, as described previously (18). Surgical specimens were then fixed in absolute cold methanol and embedded in paraffin using standard procedures. Four-micrometer cut sections were deparaffinized and rehydrated through graded concentrations of alcohol, quenched in $0.3 \% \mathrm{H}_{2} \mathrm{O}_{2}$ in methanol for $30 \mathrm{~min}$, and rinsed three times with PBS. Blocking was done using $2 \% \mathrm{NSS}$ in PBS for $30 \mathrm{~min}$ at room temperature, and the $4 \mathrm{G} 7$ antibody was applied overnight at $4^{\circ} \mathrm{C}$ in a humid chamber. Samples were then washed and incubated with the biotinylated rabbit anti-mouse antibody (Vector Laboratories, Inc.) followed by avidin-HPO. The reaction was developed using 3,3'-diaminobezidine (DAB) staining and counterstained with hematoxylin.

\section{Results}

Association of c-erbB-2 protein with the 12th armadillo repeat of $\beta$-catenin. To identify the binding site for c-erbB-2 


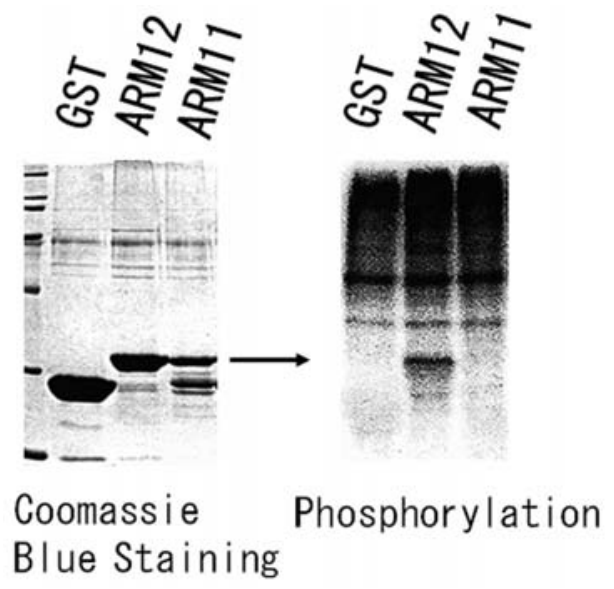

Figure 2. TGF $\alpha$ induced phosphorylation of ARM12 (arrow) in cell lysate. Metabolically labeled GST fusion proteins precipitated by Glutathione Sepharose beads were electrophorased on SDS-PAGE and detected by autoradiography (right) after coomassie blue staining (left).

a

p-arm 12: CRNEGVAT-pY-AAAVL

non-p-arm 12: c RNEGVAT-Y-AAAVL

other-p-peptide : DGQ-pY-AMTRAC

b

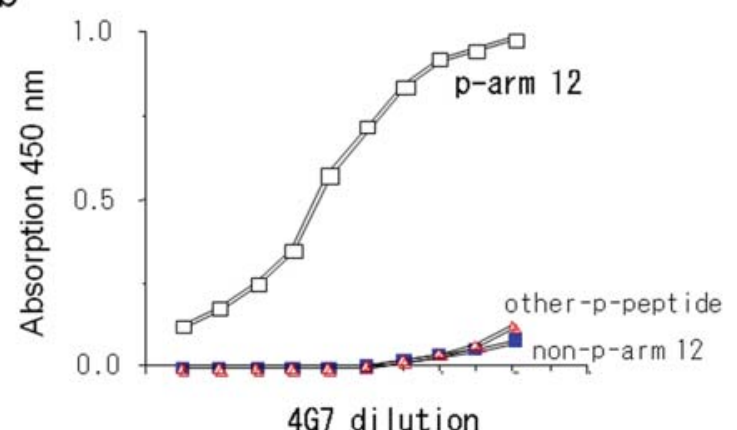

Figure 3. Specificity analysis of the monoclonal antibody 4G7, determined by ELISA. (a) Amino acid sequences of the synthetic peptide used in this experiment. p-arm12/other-p-peptide and non-p-arm12 are phosphopeptides and dephosphopeptides, respectively. The amino acid sequences of p-arm12/ non-p-arm 12 and other-p-peptide correspond to amino acids surrounding Tyrosine 654 and 86 of human B-catenin, respectively. (b) Specificity analysis of antibody 4G7 using ELISA. Microtiter plates were coated overnight with $50 \mu \mathrm{l}(1 \mu \mathrm{g} / \mathrm{ml})$ of the peptides listed in (a), blocked, and reacted with the antibody $4 \mathrm{G} 7$. Then, the reactivity was determined by measuring absorbance at $450 \mathrm{~nm}$.

protein on $\beta$-catenin, we expressed several deletion mutants of B-catenin as GST fusion proteins and coupled them to glutathione agarose beads. Bound c-erbB-2 protein was detected in TMK-1 lysates precipitated with GST fusion proteins containing full-length $\mathrm{B}$-catenin (BCT) and the C-terminal half of $B$-catenin (DN), but with neither control GST nor the N-terminal half (DC) of B-catenin (Fig. 1). GST-fusion proteins containing only the 12th armadillo repeats (ARM2,

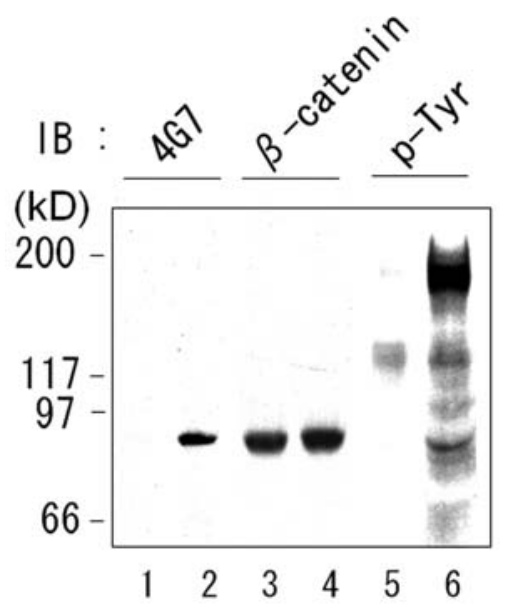

Figure 4. Immunoblot analysis of TMK-1 whole cell lysates with 4G7 (lanes 1 and 2), anti-B-catenin $\mathrm{Ab}$ (lanes 3 and 4), and anti-phosphotyrosine $\mathrm{Ab}$ (lanes 5 and 6). Prior to cell lysis, cells received PBS (lanes 1, 3, and 5) or $20 \mathrm{ng} / \mathrm{ml}$ of TGF $\alpha$ (lanes 2, 4, and 6) stimulation. The molecular markers are indicated on the left.

ARM12+11 and ARM12) remained capable of binding to c-erbB-2 protein (Fig. 1).

c-ErbB-2 activated by TGFa leads to phosphorylation of the 12 th armadillo repeat of $\beta$-catenin. We tried to elucidate whether c-erbB-2, receptor tyrosine kinase, was able to phosphorylate the 11 th or 12 th armadillo repeat of B-catenin. After TGF $\alpha$ treatment, ARM12 showed positive in autoradiography, but GST and ARM11 showed negative (Fig. 2). c-ErbB-2 activated by TGF $\alpha$ specifically associated with ARM12, and phosphorylated this region.

Production and characterization of the monoclonal antibody 4G7. A monoclonal antibody 4G7 (immunoglobulin subclass: $\mathrm{IgG} 1 \kappa)$ was developed against the synthetic peptide parm12. Reactivity of the 4G7 antibody to the synthetic peptides, p-arm12, non-p-arm 12 and other-p-peptide which were located at the $\mathrm{N}$-terminal portion of $\mathrm{B}$-catenin by ELISA is shown in Fig. 3b. The 4G7 antibody reacted specifically with the p-arm12, but not with the non-p-arm12 nor other-ppeptide (Fig. 3b).

We then examined the specificity of the $4 \mathrm{G} 7$ antibody using Western blot analysis. Fig. 4 shows the Western blot analysis using $4 \mathrm{G} 7$, anti- $\beta$-catenin and anti-phosphotyrosine antibodies in a cell lysate of a human gastric cancer cell line, TMK-1, with or without TGF $\alpha$ treatment. Transient treatment of TMK- 1 cells with TGF $\alpha$ stimulated the upregulation of 4G7 immunoreactivity at $92 \mathrm{kDa}$ (Fig. 4, lanes 1 and 2) and tyrosine phosphorylation (Fig. 4, lanes 5 and 6), although total B-catenin levels remained unchanged (Fig. 2, lanes 3 and 4).

The specificity of the 4G7 antibody was further examined by immunoprecipitation using anti-ß-catenin and anti-phosphotyrosine antibodies. Fig. 5 shows the results of immunoprecipitation analysis using anti- $\beta$-catenin and $4 \mathrm{G} 7$ antibodies on cell lysates of TMK-1 with or without TGF $\alpha$ treatment. Increased immunoreactivities of 4G7 and anti-phosphotyrosine antibodies were observed in the immunoprecipitates with the anti- $\beta$-catenin antibody after TGF $\alpha$ treatment (Fig. 5a). When 
a

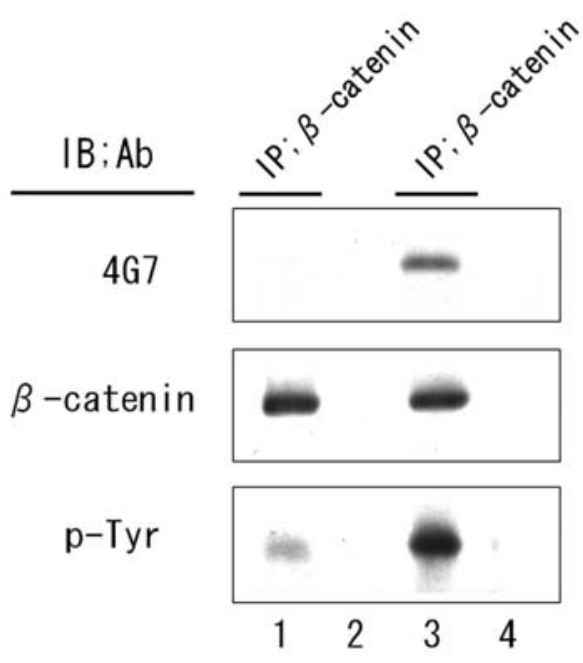

b

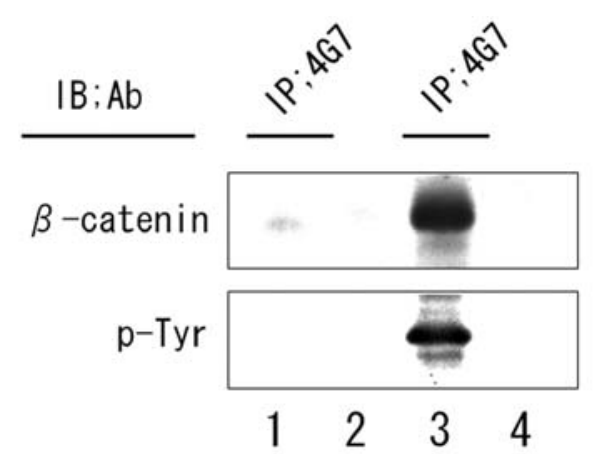

Figure 5. (a) Immunoblot analysis of immunoprecipitates by $\beta$-catenin (lanes 1 and 3) and normal mouse $\operatorname{IgG}$ (lanes 2 and 4) with 4G7, anti-Bcatenin, and anti-phosphotyrosine antibodies. (b) Immunoblot analysis of immunoprecipitates by 4G7 (lanes 1 and 3 ) and normal mouse $\operatorname{IgG}$ (lanes 2 and 4) with anti-ß-catenin, and an anti-phosphotyrosine (p-Tyr) antibody. Each immunoprecipitate from TMK-1 cells was treated without (lanes 1 and 2) or with (lanes 3 and 4) TGFa (20 ng/ml).

immunoprecipitation was performed using the 4G7 antibody, increased immunoreactivity was detected using anti- $\beta$-catenin and phosphotyrosine antibodies in the precipitates (Fig. 5b). These results indicated that the 4G7 antibody specifically recognizes the tyrosine phosphorylation of the 12th armadillo repeat of $\beta$-catenin.

Correlation between tyrosine phosphorylation at the 12th armadillo repeat of $\beta$-catenin and the association of cadherincatenin molecules in a human cancer cell line. In order to clarify the effect of tyrosine phosphorylation of the 12th armadillo repeat of $\beta$-catenin on cadherin-cell adhesion function, the association among the tyrosine phosphorylated 12th armadillo repeat of $B$-catenin, the c-erbB-2 protein, E-cadherin and B-catenin were examined in the cell lysates of TMK-1 with or without TGF $\alpha$ treatment (Fig. 6). When immunoprecipitation using the anti-E-cadherin antibody after treatment with TGF $\alpha$ and Western blot analysis using antiE-cadherin, $\alpha$-catenin, $\beta$-catenin and c-erbB-2 antibodies were performed, the association between B-catenin and E-cadherin was preserved, though that between $\alpha$-catenin and the c-erbB-2 gene product was significantly decreased (Fig. 6a, lanes 1 a

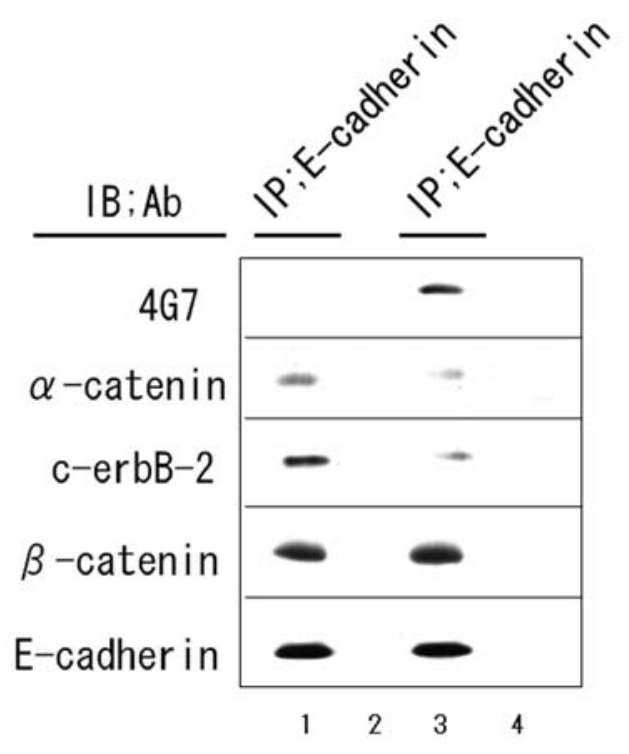

b

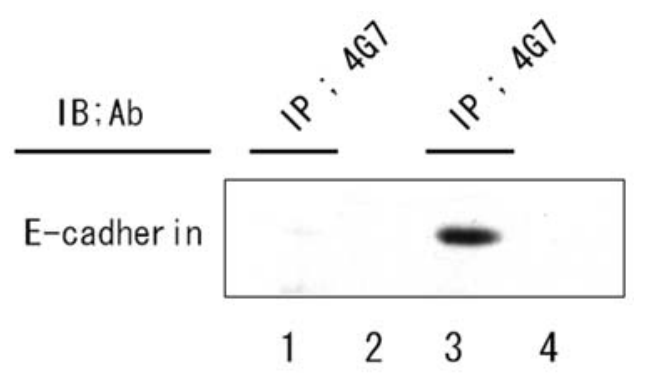

c

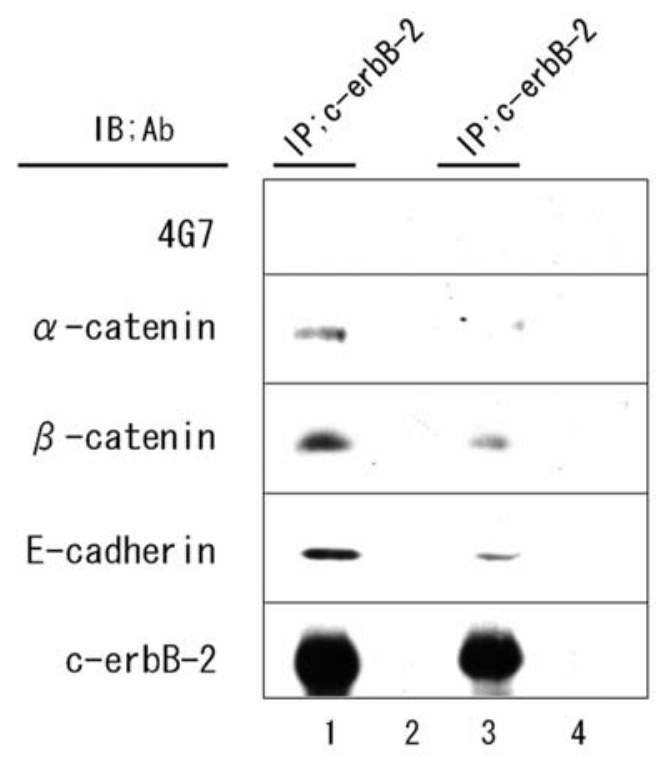

Figure 6. Immunoblot analysis of immunoprecipitates by E-cadherin (a), 4G7 (b), and c-erbB-2 gene product (c) from TMK-1 cells, respectively (lanes 1 and 3), and normal mouse $\operatorname{IgG}$ (lanes 2 and 4). (a) Immunoblot analysis with $4 \mathrm{G} 7$, anti- $\alpha$-catenin, anti-c-erbB-2, anti- $\beta$-catenin, and antiE-cadherin antibodies. (b) Immunoblot analysis with anti-E-cadherin antibody. (c) Immunoblot with $4 \mathrm{G} 7$, anti- $\alpha$ and $\beta$-catenin, anti-E-cadherin, and antic-erbB-2. Each immunoprecipitate from TMK-1 cells was treated without (lanes 1 and 2) or with (lanes 3 and 4) TGFa (20 ng/ml).

and 3). A 4G7-positive reaction was detected at the ß-catenin in the TMK-1 cell lysate only after TGF $\alpha$ stimulation. On the other hand, when immunoprecipitation analysis was 

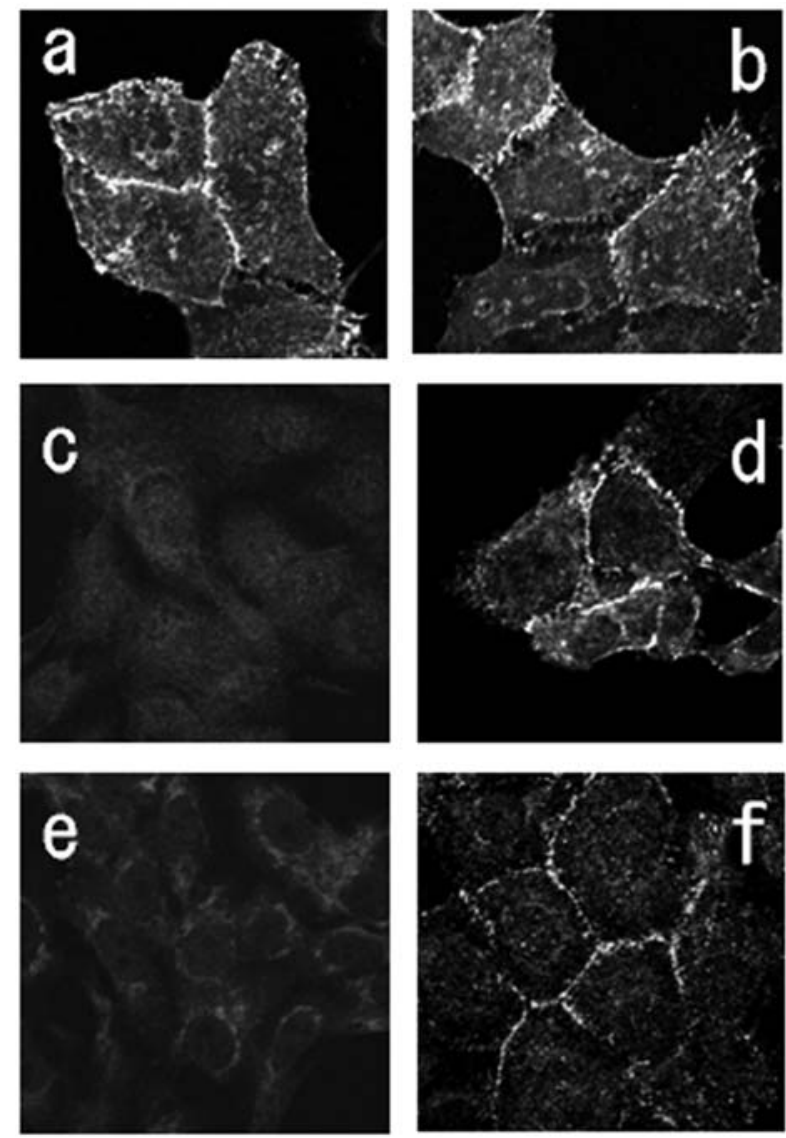

Figure 7. Indirect immunofluorescence of TMK-1 cells using anti-ß-catenin antibodies ( $\mathrm{a}$ and $\mathrm{b}$ ) or 4G7 (c-f). Cells were pretreated without ( $\mathrm{a}$ and $\mathrm{c}$ ) or with (b, d, e and f) TGFa (20 ng/ml) for $30 \mathrm{~min}$. 4G7 was preincubated with the p-arm12 peptide (e) or the non-p-arm12 peptide (f). Cells were photographed with an immunofluorescence microscope.

performed using the 4G7 antibody, E-cadherin was detected in the immunoprecipitates of cell lysates from TMK-1 cells after TGF $\alpha$ treatment (Fig. 6b, lane 3), but $\alpha$-catenin and the $c$-erbB-2 gene product were not detected (data not shown). We next performed immunoprecipitation analysis using the anti-c-erbB-2 antibody in order to investigate the association between the c-erbB-2 gene product and tyrosine phosphorylation of the 12 th armadillo repeat of $\beta$-catenin, cadherincatenin molecules, and the association between c-erbB-2 gene product and E-cadherin; $\alpha$ - and $\beta$-catenin decreased after TGF $\alpha$ treatment. Tyrosine phosphorylation of the 12th armadillo repeat of $\beta$-catenin detected by the $4 \mathrm{G} 7$ antibody did not associate with the c-erbB-2 oncogene product or $\alpha$-catenin in the immunoprecipitates using the anti-c-erbB-2 gene product and $\alpha$-catenin (data not shown) antibodies in both, with or without TGF $\alpha$ treatment.

Fig. 7 shows the immunocytochemical stainings of $\beta$ catenin and 4G7 on TMK-1 cells with or without TGF $\alpha$ treatment. TGF $\alpha$ treatment greatly enhanced the immunoreaction of $4 \mathrm{G} 7$ on the TMK-1 cell membrane (Fig. 7c and d), although TGF $\alpha$ stimulation had no obvious effect on the location of $\beta$-catenin using the anti- $\beta$-catenin monoclonal antibody (Fig. 7a and b). The specificity of this antibody was also confirmed by an absorption test using preincubation of the 4G7 antibody with synthetic peptides. As shown in Fig. 7e
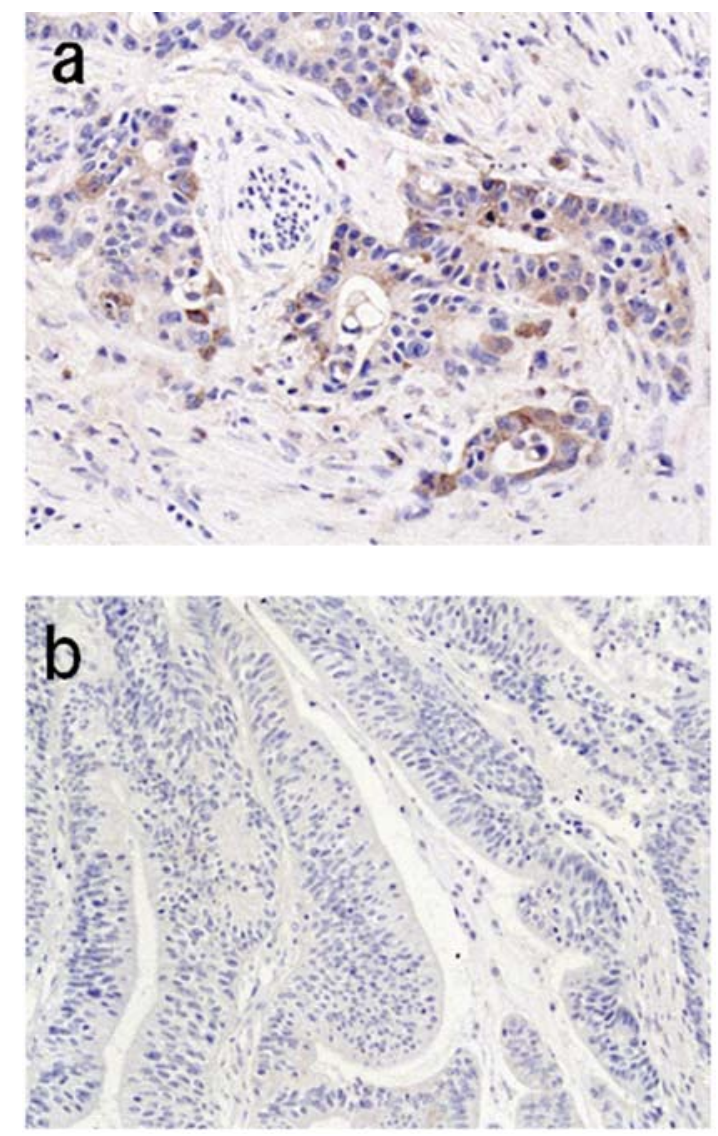

Figure 8. Immunohistochemical staining of a human colon cancer sample with 4G7. The immunoreaction of $4 \mathrm{G} 7$ was specifically observed in the cancer invasive front, where cancer cells dissociate from cancer nests and lack tight cell-cell adhesion (a), but disappeared in differentiated morphology possessing tight cell-cell connections (b).

and $\mathrm{f}$, the 4G7 immunoreaction was completely blocked by pre-incubation of the 4G7 antibody with p-arm12 peptide (Fig. 7e), but was not blocked by preincubation with the nonp-arm12 peptide (Fig. 7f).

Immunohistochemical staining of surgical specimens. Surgically resected human cancer tissues from 30 cases of colorectal cancer were immunohistochemically stained using the 4G7 antibody. Fig. 8 shows representative immunostainings of the 4G7 antibody in colon cancer. In a case of invasive tendency among the 30 cases, the immunoreaction of $4 \mathrm{G} 7$ antibody was specifically observed in the cancer-invasive front, where cancer cells dissociate from cancer nests, lacking tight cell-cell adhesion, showing membranous and cytoplasmic staining (Fig. 8a), while ß-catenin was localized at cell-to-cell connections (data not shown). In contrast, cancer cells showing a differentiated morphology possessing tight cell-cell connections revealed no immunoreactivity for the 4G7 antibody (Fig. 8b).

\section{Discussion}

In previous studies, we demonstrated that $\beta$-catenin mediated the association between the cell adhesion system and c-erbB-2 protein (12). In an attempt to clarify the interaction between 
$\beta$-catenin and c-erbB-2 protein in detail, we analyzed the binding domain of $B$-catenin and found that the 12th armadillo repeat (613-661 amino acids) of $\beta$-catenin were associated with c-erbB-2 protein and phosphorylated on tyrosine residue (Tyr-654). Thus, we produced the monoclonal antibody 4G7, which recognizes specifically the phosphorylated-654th tyrosine residue of the 12 th armadillo repeat of $B$-catenin. The stringent specificity of 4G7 for tyrosine-phosphorylated B-catenin, and lack of cross-reactivity with a broad range of phosphotyrosyl proteins, except for $\gamma$-catenin which is closely related to $B$-catenin, was verified by a series of Western blotting and peptide blocking experiments (data not shown).

The present immunoprecipitation analyses showed a close association between tyrosine phosphorylation of B-catenin at the 654th tyrosine residue and dissociation of $\alpha$-catenin and c-erbB-2 protein from $B$-catenin/E-cadherin complex. This result is consistent with a previous report that activation of the EGF receptor promoted tyrosine phosphorylation of $\beta$-catenin and dissociation between $\beta$ - and $\alpha$-catenin in normal mammary epithelial cells (19). It has been reported that activation of tyrosine kinases resulted in a loss of cadherin-mediated cellcell adhesion and an increase in the level of cytoplasmic Bcatenin $(5,20-22)$. In these reports, the integrity of cadherincatenin complex is negatively regulated by phosphorylation of B-catenin by c-erbB-2 (21) and cytoplasmic tyrosine kinases, Fer, Fyn, Yes, and Src, which phosphorylated specific tyrosine residues in B-catenin (Y654, Y142, and Y86), which lead to dissociation of the cadherin-catenin complexes.

Since the 4G7 antibody can be used to stain paraffinembedded tissue sections, it will allow direct analysis of the phosphorylation status of $B$-catenin in cellular material. This will circumvent the difficulty in predicting B-catenin phosphorylation arising from the complexity of known and possible unknown kinases for ß-catenin.

Direct staining of intact tissue for specific phosphorylated proteins using previous techniques was difficult. Conventional anti-phosphotyrosine antibodies detect not only the phosphorylated protein of interest, but also all cellular phosphotyrosine-containing proteins. Staining with conventional anti- $\beta$-catenin-specific antibodies is unable to distinguish activated, tyrosine phosphorylated B-catenin, from the inactivated type. Moreover, we can evaluate the biological information contained in the histological details by using phosphorylation specific antibodies such as the $4 \mathrm{G} 7$ antibody.

The staining pattern of 4G7 observed thus far has also been heterogeneous among the tumor cell population within a given specimen, despite the uniformity of staining with the anti- $\beta$-catenin antibody (data not shown), and is also consistently less intense than the anti- $\beta$-catenin antibody. There are a number of possible reasons for this: a) the stoichiometry of $\beta$-catenin phosphorylation may be intermediate or low; b) the affinity of 4G7 may be considerably less than that of anti- $\beta$-catenin; c) phosphorylation may not be stable to fixation and embedding. We have evidence that the third possibility is not the case. In the present study, we also developed a fixation method to preserve tyrosine phosphorylation using a tyrosine phosphatase inhibitor, sodium $o$-vanadate (18). Using this fixation method, we can also easily discriminate activated tyrosine kinase receptors from inactivated types, such as EGF-receptor and c-erbB-2. Studies by other investigators have also demonstrated immunostaining with monoclonal anti-phosphotyrosine antibodies in paraffin-embedded human breast biopsy tumor samples (23). The 4G7-positive tumors shown in the present work were obtained in the National Cancer Center Central Hospital in 1998. Tyrosine-phosphate linkage is known to be chemically very stable to wide extremes of conditions. The heterogeneous staining pattern with $4 \mathrm{G} 7$ may be due to activation of $\beta$-catenin in specific compartments within a given tumor, e.g., in regions where the receptor has access to an activating ligand. These factors may explain some of the inconsistencies in the clinical data regarding the prognostic value of overexpression. For example, overexpression in the presence of ligands may elicit a proliferative signal and hence a poor prognosis, whereas overexpression in the absence of ligands may induce tumor cells toward terminal differentiation and thus improve prognosis. This paradigm could also explain the observation that ß-catenin overexpression occurs in a much higher proportion of in situ malignancies than invasive ones. For example, if a differentiation-inducing ligand produced in the stroma were inaccessible to well differentiated adenocarcinoma cells, then ß-catenin overexpression could drive proliferation during the in situ phase, but then elicit differentiation upon invasion of the stroma, at which point negative selection pressure for B-catenin expression would prevail.

4G7 may be an analytical tool that should facilitate the search for answers to many of these questions. It bypasses the need to individually evaluate each of the growth factor inputs in order to predict signaling activity and, by marking the anatomic locations at which B-catenin is normally active, will help elucidate the source of the most important agonists and the time at which they act. Of the 18 tyrosine residues in B-catenin, the specific phosphopeptide recognized by $4 \mathrm{G} 7$ is known to be significant for binding of the $c$-erbB-2 gene product. Besides tumor biological interest, correlation of the clinicopathological characteristics of tumors with $4 \mathrm{G} 7$ staining may illustrate the role of $\beta$-catenin in the biology of these tumors. Understanding the precise role of $\beta$-catenin may become important because of the great potential of tyrosine phosphorylated $\beta$-catenin as a diagnostic marker.

We have demonstrated that B-catenin Tyr-654 phosphorylation was observed at the focal dedifferentiated area of the invasive front in human colon cancer tissues. Colonic cancers with focal dedifferentiation showed metachronous liver metastasis. The 4G7 antibody can likewise be used to elucidate the biology of $\beta$-catenin during development. This strategy for elucidating tumor function using antibodies to activated proteins is applicable in the analyses of other phosphoproteins and the role of tyrosine protein kinases in other malignancies. A $\beta$-catenin phosphorylation assay using 4G7 may also be useful in screening for a ß-catenin phosphorylating ligand or tyrosine kinases.

\section{Acknowledgments}

This research was supported in part by a Grant-in-Aid for the second term Comprehensive 10-Year Strategy for Cancer Control from the Ministry of Health, Labor, and Welfare, Japan. 


\section{References}

1. Takeichi M: Cadherin cell adhesion receptors as a morphogenetic regulator. Science 251: 1451-1455, 1991.

2. Vleminckx K, Vakaet L Jr, Mareel M, Fiers W and van Roy F: Genetic manipulation of E-cadherin expression by epithelial tumor cells reveals an invasion suppressor role. Cell 66: 107-119, 1991.

3. Aberle H, Butz S, Stappert J, Weissig H, Kemler R and Hoschuetzky $\mathrm{H}$ : Assembly of the cadherin-catenin complex in vitro with recombinant proteins. J Cell Sci 107: 3655-3663, 1994.

4. Mareel M, Boterberg T, Noe V, Bruyneel E and Bracke M: Molecular aspects of cancer metastasis: extracellular regulation of the E-cadherin/catenin complex. Int J Dev Biol (Suppl) 1: S65-S66, 1996.

5. Piedra J, Miravet S, Castaño J, et al: p120 catenin-associated Fer and Fyn tyrosine kinases regulate beta-catenin Tyr-142 phosphorylation and beta-catenin-alpha-catenin interaction. Mol Cell Biol 23: 2287-2297, 2003.

6. Birchmeier W and Behrens J: Cadherin expression in carcinomas: role in the formation of cell junctions and the prevention of invasiveness. Biochim Biophys Acta 1198: 11-26, 1994.

7. Zschiesche W, Schonborn I, Behrens J, et al: Expression of E-cadherin and catenins in invasive mammary carcinomas. Anticancer Res 17: 561-567, 1997.

8. Matsuyoshi N, Hamaguchi M, Taniguchi S, et al: Cadherinmediated cell-cell adhesion is perturbed by $\mathrm{v}$-src tyrosine phosphorylation in metastatic fibroblasts. J Cell Biol 118: 703-714, 1992.

9. Behrens J, Vakaet L, Friis R, et al: Loss of epithelial differentiation and gain of invasiveness correlates with tyrosine phosphorylation of the E-cadherin/beta-catenin complex in cells transformed with a temperature-sensitive v-SRC gene. J Cell Biol 120: 757-766, 1993.

10. Hamaguchi M, Matsuyoshi N, Ohnishi Y, et al: p60v-src causes tyrosine phosphorylation and inactivation of the N-cadherincatenin cell adhesion system. EMBO J 12: 307-314, 1993.

11. Shibamoto $\mathrm{S}$, Hayakawa M, Takeuchi $\mathrm{K}$, et al: Tyrosine phosphorylation of beta-catenin and plakoglobin enhanced by hepatocyte growth factor and epidermal growth factor in human carcinoma cells. Cell Adhes Commun 1: 295-305, 1994.
12. Ochiai A, Akimoto S, Kanai Y, et al: c-erbB-2 gene product associates with catenins in human cancer cells. Biochem Biophys Res Commun 205: 73-78, 1994.

13. Kanai Y, Ochiai A, Shibata T, et al: c-erbB-2 gene product directly associates with beta-catenin and plakoglobin. Biochem Biophys Res Commun 208: 1067-1072, 1995.

14. Shibata T, Ochiai A, Kanai Y, et al: Dominant negative inhibition of the association between beta-catenin and c-erbB-2 by $\mathrm{N}$-terminally deleted beta-catenin suppresses the invasion and metastasis of cancer cells. Oncogene 13: 883-889, 1996.

15. Shibata T, Gotoh M, Ochiai A and Hirohashi S: Association of plakoglobin with APC, a tumor suppressor gene product, and its regulation by tyrosine phosphorylation. Biochem Biophys Res Commun 203: 519-522, 1994.

16. Galfre $\mathrm{G}$ and Milstein C: Preparation of monoclonal antibodies: strategies and procedures. Methods Enzymol 73: 3-46, 1981.

17. Engvall E: Enzyme immunoassay ELISA and EMIT. Methods Enzymol 70: 419-439, 1980.

18. Akimoto S, Ochiai A, Inomata $\mathrm{M}$ and Hirohashi S: Expression of cadherin-catenin cell adhesion molecules, phosphorylated tyrosine residues and growth factor receptor-tyrosine kinases in gastric cancers. Jpn J Cancer Res 89: 829-836, 1998.

19. Takahashi K, Suzuki K and Tsukatani Y: Induction of tyrosine phosphorylation and association of beta-catenin with EGF receptor upon tryptic digestion of quiescent cells at confluence. Oncogene 15: 71-77, 1997.

20. Roura S, Miravet S, Piedra J, Garcia de Herreros A and Dunach M: Regulation of E-cadherin/Catenin association by tyrosine phosphorylation. J Biol Chem 274: 36734-36740, 1999.

21. Bonvini P, An WG, Rosolen A, et al: Geldanamycin abrogates ErbB2 association with proteasome-resistant beta-catenin in melanoma cells, increases beta-catenin-E-cadherin association, and decreases beta-catenin-sensitive transcription. Cancer Res 61: 1671-1677, 2001

22. Xu G, Craig AW, Greer P, et al: Continuous association of cadherin with beta-catenin requires the non-receptor tyrosinekinase Fer. J Cell Sci 117: 3207-3219, 2004.

23. Tsarfaty I, Resau JH, Rulong S, et al: The met proto-oncogene receptor and lumen formation. Science 257: 1258-1261, 1992. 